\title{
REVIEW
}

\section{Emergency asthma inhalers in school}

\section{R Reading, T Jones, C Upton}

Despite there being a lack of direct evidence of the effectiveness of providing emergency inhalers to schools, the balance of evidence at present suggests the benefits outweigh any possible harm. However, unless UK prescribing law or its interpretation is changed, this will remain an action which opens teachers, nurses, and doctors to possible legal and professional sanctions, and may nullify their institutional or professional indemnity. As a consequence, provision will remain patchy and research into the value of emergency inhalers will be inhibited. A position statement from one or more responsible organisations such as the Royal College of Paediatrics and Child Health, the British Thoracic Society, or the British Paediatric Respiratory Society could persuade a reassessment from the Medicines Control Agency. This is also an issue which could be addressed in the forthcoming National Service Framework for children.

See end of article for authors' affiliations

Correpondence to: Dr R Reading, School of Medicine, Health Policy and Practice, University of East Anglia, Norwich NR4 7TJ, UK.

r.reading@uea.ac.uk

Accepted

5 October 2002
A pproximately 20 children of school age die each year from asthma in England and Wales. ${ }^{1}$ An important aspect of management is prompt and appropriate treatment of an acute attack. Much attention has been given to education of parents and young people in the emergency management of attacks, but less to schools where children spend a considerable proportion of their waking lives. A number of districts in the UK have introduced asthma policies for schools, which include the supply of emergency inhaler kits for the treatment of any child who develops an acute attack of breathlessness.

This paper describes attempts to introduce such a policy and the legal difficulties which ultimately prevented us from supplying emergency inhalers to schools. We then review the literature on the effectiveness of emergency inhalers, and of wider aspects of asthma policies in schools. We comment on the legal position, and conclude by discussing whether the evidence justifies changes to the way prescribing law is applied.

\section{NORFOLK SCHOOLS ASTHMA POLICY}

In 1998 a local health and education initiative began to develop an asthma policy for schools which would cover prevention, management of chronic symptoms, and recognition and management of acute exacerbations. The initiative was supported by health professionals, teachers, all local NHS bodies, and the local education authority. Although the policy recommended that children used their own inhalers wherever possible, one aspect was the supply to schools of an unnamed metered dose inhaler of a $\beta$ agonist bronchodilator and an appropriate spacer device for the emergency treatment of attacks of wheeze or breathlessness. The rationale for supplying an emergency inhaler is that children may not have their own inhalers readily available, their inhalers may be an inappropriate formulation for treating severe wheeze, or their attack of wheeze may be unexpected. Schools were to be offered training in the recognition of symptoms of an acute attack, and given advice about administering 10 puffs of inhaler over 10 minutes, monitoring response, and seeking emergency medical attention.

The supply of an emergency inhaler was considered a key part of the policy, not purely because prompt treatment should reduce morbidity-and might even save a life-but because it added credibility to the overall policy. One of the chief anxieties of teachers is about children having untreated severe acute attacks. ${ }^{2}$ Without a means of treating these rare emergencies, teachers might have less faith in other aspects of the policy designed to improve day to day management for the majority of children.

All parties to the policy, including the local education authority, supported the provision of emergency inhalers, but were concerned about how this could be implemented legally. Our own legal advice concluded that although supplying unnamed bronchodilator inhalers to schools was outside the law, and any doctor doing this would be open to the full sanctions of the General Medical Council, the likelihood of any action against the doctor or their employers was extremely low because the policy had been introduced openly, agreed locally, was based on evidence of effectiveness, seen as good practice, and the balance of risks was strongly on the side of overall benefit.

Around this time the Crown report advised on the prescription and supply of medications to unnamed patients under a protocol. ${ }^{3}$ We felt that the supply and use of emergency inhalers in schools might be considered under this guidance. However, the subsequent government guidance explicitly excluded non-health professionals as being able to administer medications without a named prescription. ${ }^{5}$ We sought clarification from the Department of Health; the Medicines Control Agency replied constructively, but nevertheless pointed out that what we were proposing was unlawful and could not be countenanced.

\section{LITERATURE REVIEW}

We searched the literature for publications relating to the effectiveness of emergency inhalers, experience in using asthma policies in schools, and supply of emergency inhalers to schools. We searched the Medline database via Ovid (19662002) and through PubMed on the Internet. We 
identified further references from these papers. We searched the Cochrane database. We used our personal knowledge of the literature and papers identified by us in developing the asthma policy. We consulted expert colleagues.

\section{Effectiveness of metered dose inhalers in treatment of acute asthma}

Short acting inhaled $\beta$ agonist bronchodilators are the first line treatment of choice for acute attacks of asthma in childhood. ${ }^{6} \beta$ Agonist bronchodilators taken by metered dose inhaler are not associated with serious adverse effects compared with oral or nebulised use of these drugs. ${ }^{7}$ Metered dose inhalers with an appropriate large volume spacer device are as effective, if not more so, than nebulised bronchodilators in improving both short term lung function ${ }^{8}$ and longer term measures of recovery. ${ }^{\circ}$ A recently updated Cochrane review including data from trials involving 880 children found that treatment with $\beta$ agonists from a metered dose inhaler with a holding chamber produced outcomes that were at least equivalent and may have some advantages over nebuliser delivery in acute asthma.$^{10}$ They commented that most trials took place in hospital and that further research is needed to confirm whether these findings are applicable in community settings. The current UK guidelines on the community treatment of mild to moderate acute attacks in young children call for up to 10 puffs of inhaled $\beta$ agonist bronchodilator through a metered dose inhaler with spacer. ${ }^{6}$

\section{Effectiveness of school asthma policy}

Many studies have described the lack of knowledge of teachers and poor coordination of care for asthmatic children in schools. ${ }^{21-16}$ Most of these papers have concluded that a formal asthma policy for schools was required. However, a randomised intervention study of the effectiveness of introducing a schools asthma policy showed little effect on asthma morbidity in children, although teachers' understanding and management of asthma did improve. ${ }^{17}$

\section{Effectiveness of emergency inhalers in school}

There are no randomised trials to our knowledge on the effectiveness of emergency inhalers in a school setting. However, there are published guidelines on asthma policies for schools from Australia and New Zealand, which include the provision of an emergency "first aid" kit consisting of a metered dose inhaler of a bronchodilator and a spacer device. ${ }^{18}$ Asthma crisis management is reported to have improved after a training programme in Australia which included the provision of emergency inhalers. ${ }^{19}$ Ten per cent of asthmatic children are reported to have needed emergency treatment in this study, although it is not clear whether the emergency inhaler supplied as part of the school's first aid kit was used on each of these occasions. An evaluation of the use of emergency inhalers in a UK district which had issued these to schools, published in abstract form, found that the inhaler had been used in over 50\% of schools, and had been used more than once in over a third of schools. ${ }^{20}$ Responses from parents and staff had been positive, although no data on morbidity were reported.

\section{Introduction of emergency inhalers to schools}

In Newcastle, Australia, over $90 \%$ of schools included an emergency inhaler and spacer in their school first aid kit after a series of training seminars. ${ }^{21}$ This presumably reflects the adoption of the Australia and New Zealand Thoracic Society policy on asthma management in schools. ${ }^{18}$ In the UK we believe the first scheme for providing emergency inhalers to schools was in Southampton ${ }^{22}$; two other centres, Cornwall and North Staffordshire, have also reported their experience. ${ }^{23}$ All these papers stress the importance of setting the provision of emergency inhalers in the context of an overall asthma policy for schools, the need for a running programme of training and updating for teachers, and the relative safety of emergency generic bronchodilator treatment in breathless children. No adverse effects are described, although a theoretical concern is that children may be less likely to carry their own inhaler if an emergency inhaler at school is available.

\section{THE LAW}

The law is straightforward. Inhaled bronchodilators are prescription only medicines. Under the 1968 Medicines Act these can only be supplied in accordance with a doctor's prescription to a named patient. It is on this basis that the supply to a school for use in an emergency and any subsequent administration would be illegal.

The recommendations of the Crown Report ${ }^{4}$ and their subsequent adoption by the government ${ }^{5}$ cover the supply and administration of medicines to patients who may not initially be identified. Clear guidance is given about what needs to be included in protocols, formally known as patient group directions, in order for medicines to be administered. School policy and training materials could easily include all the mandatory information needed for an approved group protocol, such as descriptions of the patients included and excluded from the instructions, the circumstances under which the medicine should be administered, adverse reactions, and follow up actions, but the law excludes non-health professionals.

The options are therefore:

- To supply emergency inhalers to schools anyway, providing clear guidance and ongoing training and advice, with a paediatrician or public health doctor taking clinical responsibility. This is not permissible legally but is unlikely to result in any sanctions.

- To write a patient group direction for emergency inhaler use for situations where a recognised health professional such as a nurse is always on site. This is impractical for most schools, but might be possible in some larger secondary schools and independent schools where a school nurse is employed.

- To compile a list of all asthmatic children in the school and, with their parent's and general practitioner's agreement, to issue a mass prescription and clear instructions for these named children. This would be analagous to current arrangements for any emergency treatment, but would bring all the named children into the provisions of a single health care plan. ${ }^{25}$ It would require a high degree of bureaucracy, and is still not strictly within the law. It also assumes we can identify all children likely to have an acute attack of asthma, which manifestly we can not.

- To arrange for general practitioners to supply an extra inhaler of the child's usual bronchodilator to be held by the school for use in an emergency when they do not have their own. This would require an individual health care plan for each child and would be a logistic nightmare for schools who would be holding large numbers of different named inhalers, some of which may not be appropriate for use in an acute attack (for example dry powder inhalers).

In our view none of these are realistic or desirable. Districts wishing to implement a policy of supply of emergency inhalers to schools have no real option of working within the law.

\section{ACKNOWLEDGEMENTS}

We are grateful to all members of the Norfolk Schools Asthma Policy group who developed the policy, particularly Carole Farrow, pharmacist, and Alison Betteridge, paediatric respiratory nurse, to Anne Ryan of the Medicines Control Agency who advised on interpretation of the legal position, to Martin Samuels and John Warner for information about their work in Staffordshire and Southampton, and to David Hall whose interest prompted this article.

\section{Authors' affiliations}

R Reading, School of Medicine, Health Policy and Practice, University of East Anglia, UK

T Jones, C Upton, Norfolk and Norwich University Hospital, UK 


\section{REFERENCES}

1 Office for National Statistics. Mortality statistics: cause. Series DH2. London: The Stationary Office.

2 Brookes J, Jones K. Schoolteachers perceptions and knowledge of asthma in primary schoolchildren. Br J Gen Pract 1992:42:504-7.

3 Stephenson T. Implications of the Crown Report and nurse prescribing Arch Dis Child 2000;83: 199-202.

4 Department of Health. Review of prescribing, supply and administration of medicines. Report on the supply and administration of medicines under group protocols. London: Department of Health, April 1998.

5 Department of Health. Patient group directions [England only]. HSC2000/026. London: Department of Health, August 2000.

6 The British Thoracic Society et al. The British guidelines on asthma management: 1995 review and position statement. Thorax (Suppl) 1997;52:S1-21.

7 Suissa S, Hemmelgarn B, Blais L, et al. Bronchodilators and acute cardiac death. Am J Respir Crit Care Med 1996;154:1598-602.

8 Lin Y-Z, Hsieh K-H. Metered dose inhaler and nebuliser in acute asthma. Arch Dis Child 1995;72:214-18.

9 Dewar AL, Stewart A, Cogswell JJ, et al. A randomised trial to assess the relative benefits of large volume spacers and nebulisers to treat acute asthma in hospital. Arch Dis Child 1999;80:421-3.

10 Cates C J, Rowe BH, Bara A. Holding chambers versus nebulisers for beta-agonist treatment of acute asthma (Cochrane review). In: The Cochrane Library, Issue 2. Oxford: Update Software, 2002.

11 Hill RA, Britton JR, Tattersfield AE. Management of asthma in schools. Arch Dis Child 1987:62:414-15.

12 Bevis M, Taylor B. What do school teachers know about asthma? Arch Dis Child 1990;65:622-5.

13 Smith EC, Kendrick AH. A survey of asthma in schools in Avon. J R Coll Physicians Lond 1992;26:65.

14 Pugh E, Mansfield K, Clague H, et al. Children with asthma in schools: an opportunity for "healthy alliance" between health and education authorities. Health Trends 1995:27:127-9.

15 Fillmore EJ, Jones N, Blankson JM. Achieving treatment goals for children with asthma. Arch Dis Child 1997;77:420-2.

16 Hussey J, Cahill A, Henry D, et al. National school teachers knowledge of asthma and its management. Ir J Med Sci 1999;168:174-9.

17 Hill R, Williams J, Britton J, et al. Can Morbidity associated with untreated asthma in primary school children be reduced: a controlled intervention study. BM 1991;303:1169-74.

18 The Asthma Special Interest Group, Thoracic Society of Australia and New Zealand. Position Paper: A national policy on asthma managemen for schools. J Paediatr Child Health 1994;30:98-101

19 Shah S, Gibson PG, Wachinger S. Recognition and crisis management of asthma in schools. J Paediatr Child Health 1994:30:312-15.

20 Samuels MP, Scotton C. The use of emergency inhalers in schools [abstract]. Arch Dis Child 1999;80(suppl):A18

21 Hazell J, Henry RL, Francis JL, et al. Teacher initiated improvement of asthma policy in schools. J Paediatr Child Health 1995;31:519-22.

22 Coleman H, Finlay FO, Gregson RK, et al. Asthma management in Southampton schools. Education and Health 1995:13:12-14.

23 Waldron J, Denn D, Oliver $\mathrm{H}$, et al. An asthma policy for schools in Cornwall. Paediatr Nurs 1999;11:6-8

24 Scotton C, Samuels M. Training and treatment for asthma in schools. The Asthma Journal 2000;5:28-31.

25 Department for Education and Employment. Supporting pupils with medical needs in schools. London: Department for Education and Employment, 1996.

\section{WEB TOP TEN FOR FEBRUARY 2003}

www.archdischild.com

These articles scored the most hits on $A D C^{\prime}$ s website during February 2003

1 Classification of child abuse by motive and degree rather than type of injury

D P Southall, M P Samuels, M H Golden

February 2003;88:101-4.

2 Importance of timing of risk factors for cerebral oedema during therapy for diabetic ketoacidosis

A P C P Carlotti, D Bohn, M L Halperin

February 2003;88:170-3

3 Difficult asthma in children

S A McKenzie, A Bush

February 2003;88: 168-9

4 Preventing sleeping problems in infants who are at risk of developing them

M Nikolopoulou, I St James-Roberts

February 2003;88:108-115

5 Survey of adrenal crisis associated with inhaled corticosteroids in the United Kingdom

G R G Todd, C L Acerini, R Ross-Russell, et al

December 2002;87:457-6

6 Tonsillectomy

M Burton

February 2003;88:95-6

7 Kawasaki disease: an evidence based approach to diagnosis, treatment, and proposals for future research P A Brogan, A Bose, D Burgner, et al April 2002;86:286-90

8 Resuscitation training of paediatricians

F Jewkes, B Phillips

February 2003;88: 11 18-21

9 Breast feeding and respiratory morbidity in infancy: a birth cohort study

W H Oddy, P D Sly, N H de Klerk, et al

March 2003;88:224-8

10 Acute disseminated encephalomyelitis: recognition in the hands of general paediatricians M Stonehouse, G Gupte, E Wassmer, et al February 2003;88:122-4 